Nuffield Department of Primary Care Health Sciences, University of Oxford, UK

2 TB Proof, South Africa

Correspondence to: $\mathrm{H}$ van der Westhuizen helene.vanderwest huizen@gtc.ox.ac.uk Cite this as: BMJ 2020;370:m3021 http://dx.doi.org/10.1136/bmj.m3021

Published: 19 August 2020

\title{
Face coverings for covid-19: from medical intervention to social practice
}

\begin{abstract}
Helene-Mari van der Westhuizen and colleagues argue that face coverings should be considered not as medical equipment but as a social practice informed by norms and expectations
\end{abstract}

Helene-Mari van der Westhuizen, ${ }^{1,2}$ Koot Kotze, ${ }^{1,2}$ Sarah Tonkin-Crine, ${ }^{1}$ Nina Gobat, ${ }^{1}$ Trisha Greenhalgh

Key messages

- Face coverings used by the public are now widely recommended as source control during the covid-19 pandemic

- The dominant narrative driving policy has viewed face coverings as a medical intervention and evaluated their effectiveness from an infection control perspective

- Face coverings are also a social practice and carry a range of meanings in different settings

- Policies to encourage uptake should reflect the complex and contested sociocultural meanings of covering the face and draw on these to promote their use

Covering the mouth and nose is a public health measure designed to capture respiratory droplets from the wearer (who may not have symptoms) to reduce transmission of respiratory infections. ${ }^{1}$ Debates about whether face coverings should be used have framed them largely as a medical intervention with benefits and harms. Although the majority of countries and public health agencies now recommend or mandate face coverings against covid-19, viewing face coverings through a medical narrative still dominates. $^{1-4}$

Many public facing infographics on face coverings describe the initial steps as follows: "clean your hands before touching the mask, inspect the mask for damage or if dirty, adjust the mask to your face without leaving gaps on the side." ${ }^{5}$ Given that social practices are deeply held and passionately defended, we hypothesise that uptake of face coverings is likely to be advanced by downplaying the medical narrative about "standards," "donning and doffing," "decontamination," and "risk.” For successful uptake, face coverings need to be grounded in the social and cultural realities of affected communities.

We use the term "medical mask" to refer to a device that meets particular standards and is intended primarily for healthcare workers (but may also be recommended for the public). The term "face covering" refers to anything that covers the face, including homemade or commercially sold coverings (typically made of cloth, but sometimes from paper or other materials) intended primarily for the public. Different countries opted for different approaches as covid-19 spread. China and South Korea, for example, rapidly increased production of medical masks for use by the public, whereas the Czech Republic and Thailand were early adopters of cloth face coverings to conserve supplies of medical masks for health workers. $^{2}$

\section{An infection control tool}

Framed medically, a face covering is either personal protective equipment (to protect the wearer) or a means of source control (to prevent the spread of illness). Manufacturing of infection control equipment is subject to stringent quality standards with distribution and procurement typically organised on a national level.

Almost all randomised controlled trials of face coverings have been done in healthcare facilities and addressed their efficacy in protecting the wearer from infection, not as source control. ${ }^{6}$ But drawing on the same evidence base for healthcare facilities and community settings has limitations. ${ }^{6}$ Medical narratives favour interventions with fixed characteristics and an effect size that can be determined through controlled experiments. Public health measures aimed at whole populations seldom have randomised controlled trial evidence available, and such trials may not be ethical or practical. ${ }^{6-8}$ For example, a challenge of assessing face coverings as source control is that the people in the trial are not those in whom the effect would need to be measured.

This medical narrative includes concerns about the public not being able to use face coverings safely. Standardisation in making, using, and cleaning face coverings at population level is challenging when people have access to vastly different resources. In such circumstances, making the task of putting on and taking off a face covering feel complicated and hazardous risks making it more difficult to implement.

\section{Social practice}

Framed socioculturally, face coverings are clothing or accessories. Wearing one is a social practice-a behaviour that has a particular meaning in a particular society. ${ }^{9}$ A social practice involves human agency based on the person's (perhaps imperfect) knowledge-for example, their assessment of whether a face covering is effective-and what they view as its symbolic meaning. The latter will be influenced by social expectations (eg, what we expect a shop assistant, bus driver, or nurse to be wearing), norms (what is viewed as morally correct and as right and proper behaviour), and laws and regulations (is wearing a face covering mandatory?). Uptake of the policy will be influenced by practical matters such as availability of resources (is it easy, and a priority, to make or obtain one?). 
In the current global pandemic, there are examples of face coverings adapting to cultural traditions. In India, a loose end of a piece of clothing, from a saree, or a loose piece of cloth, a "dupatta," has become more commonly used to cover the face during covid-19. ${ }^{10}$

Face coverings have been associated with assuming a different identity (worn by a superhero), avoiding recognition and persecution (worn by a criminal), to exhibit modesty (expected of women in some cultures), having an infectious disease (worn by a patient), and for cultural ceremonies and processions (worn by those who are celebrating). Covering the face may also be viewed in practical terms as protection against pollution, dust, pollen, or wildfires. ${ }^{11} 12$

In some countries, predominantly in Asia, face coverings have been widely used in public before this pandemic, possibly owing to past experience with respiratory virus epidemics and, perhaps, a strong cultural emphasis on interdependence instead of independence. ${ }^{13}$ It might also be linked to cultural meaning systems that emphasise the boundary between a clean and pure inner self and a potentially polluted outside (similar to the removal of shoes on entering the home, for example). ${ }^{12}$

Cloth face coverings are usually characterised by personalisation and a bottom-up approach to manufacturing and distribution. They can be homemade, from an existing piece of clothing or purchased from a store for convenience, to display a brand or to match an outfit (fig 1). There are examples of face coverings with animal noses, creating a sense of playfulness that may make them more acceptable to children. Activists have placed slogans (such as Black Lives Matter) on their face coverings that emphasise their role in displaying identity. Designer labels have produced expensive, high fashion face coverings. 


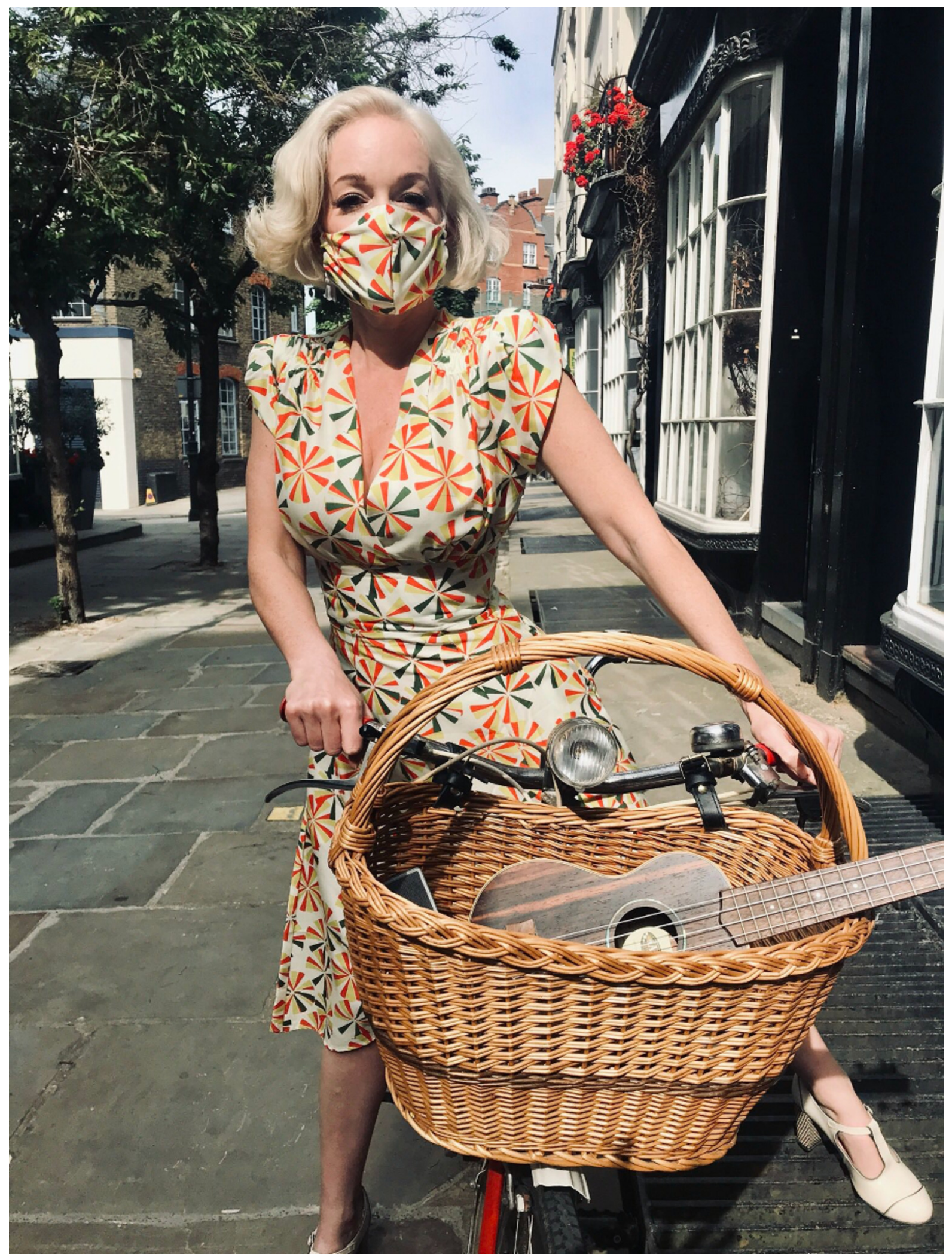

Fig 1 | London Jazz singer Kitty LaRoar wearing a matching face covering with her vintage outfit. Photo credit: Nicholas Shankland.

The wide variation in materials and style raises questions about the efficacy and reliability of face coverings. ${ }^{1}$ Public health policy must consider the trade-off between efficacy and compliance (a face covering that is $100 \%$ effective at preventing transmission but only

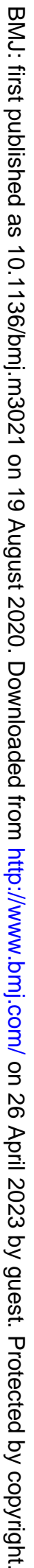

worn by $10 \%$ of the population will have less impact that one that is $50 \%$ effective but worn by $95 \%$ of the population). 


\section{Shifting the narrative}

During the covid-19 pandemic, wearing face coverings is being rapidly introduced as a public health intervention in countries with no cultural tradition of doing so. For successful uptake, such interventions need to be grounded in the social and cultural practices and realities of affected communities, and campaigns should not only inform, but also work to shape new sociocultural norms (table 1).

Table 1 | Shifting public health messaging about face coverings from being seen as a medical intervention to a social practice

\begin{tabular}{|c|c|c|}
\hline Topic & Medical intervention & Social practice \\
\hline Focus and message & $\begin{array}{l}\text { Individual wearer: protect yourself and in doing so, you may } \\
\text { also protect others }\end{array}$ & Community: Protect others and they will also protect you \\
\hline Goal & $\begin{array}{l}\text { Risk reduction: reducing or eliminating risk of infection to the } \\
\text { wearer }\end{array}$ & $\begin{array}{l}\text { Population benefit: reducing the overall level of transmission } \\
\text { on population level }\end{array}$ \\
\hline Selecting & $\begin{array}{l}\text { Function: ensure that the face covering meets particular filtration } \\
\text { and performance standards }\end{array}$ & $\begin{array}{l}\text { Acceptability: choose a face covering that is easy to make or } \\
\text { buy and has a design that you would like to wear. Aim to use } \\
\text { one with three layers, but a face covering with fewer layers is } \\
\text { better than wearing no face covering }\end{array}$ \\
\hline Putting on, taking off, and wearing & $\begin{array}{l}\text { Infection control: follow strict donning and doffing procedures } \\
\text { (use straps; do not touch front of face covering). Test for fit. } \\
\text { Avoid self-contamination by touching your face covering. } \\
\text { Remove the covering after a specified time period or when there } \\
\text { is visible soiling or damage }\end{array}$ & $\begin{array}{l}\text { Comfort and cleanliness: make sure it covers your mouth and } \\
\text { nose and is comfortable to wear without repeatedly adjusting } \\
\text { it. Change your face covering if it becomes dirty. Wear a clean } \\
\text { face covering each day }\end{array}$ \\
\hline Cleaning & $\begin{array}{l}\text { Storage and decontamination: store soiled coverings according } \\
\text { to strict procedures. Wash the face covering at a specified } \\
\text { temperature }\end{array}$ & $\begin{array}{l}\text { Laundering: remove your face covering when you get home } \\
\text { and put it in the laundry. Wash it with your other clothes }\end{array}$ \\
\hline Relating to others & Avoid risk: do not share your face covering with others & $\begin{array}{l}\text { Promote benefit: make sure your friends, family, and vulnerable } \\
\text { members of society have face coverings too-eg,through } \\
\text { community making and distribution schemes }\end{array}$ \\
\hline Environmental concerns & $\begin{array}{l}\text { Careful disposal: discarded disposable face coverings are an } \\
\text { environmental hazard; they must be properly destroyed in } \\
\text { accordance with regulations }\end{array}$ & $\begin{array}{l}\text { Sustainability: have two or three reusable face coverings that } \\
\text { can be washed and used again, which could reduce costs to } \\
\text { the user and avoid waste }\end{array}$ \\
\hline
\end{tabular}

Public messages around face coverings help conceptualise who typically wears a face covering and the moral valence of this action. At the start of the covid-19 pandemic, people of Asian ethnicity were stigmatised in the United Kingdom for wearing face coverings, as if they were carriers of disease who threatened the safety of others. ${ }^{14}$ In the US, mandating of face coverings has been interpreted as an infringement of civil liberties and autonomy, with critics using the term "muzzle" to depict dehumanisation of the individual by the state. ${ }^{15}$ Some public figures, including the president of the United States, initially refused to wear a face covering, depicting wearing a mask as a sign of weakness and refusing to wear a mask as an assertion of authority. ${ }^{16}$
For a policy of public masking to succeed, negative depictions of the social meaning and moral worth of face coverings need to be actively reframed. Given that the main purpose of face coverings by the public is source control, wearers could be depicted as altruistic or even as protectors. This could create new symbolism around wearing, making, and distributing face coverings that is based on social responsibility and solidarity against a common threat $^{17}$ (fig 2). The Czech Republic and South Africa have taken a social practice approach to promoting the domestic production and use of face coverings (box 1). 


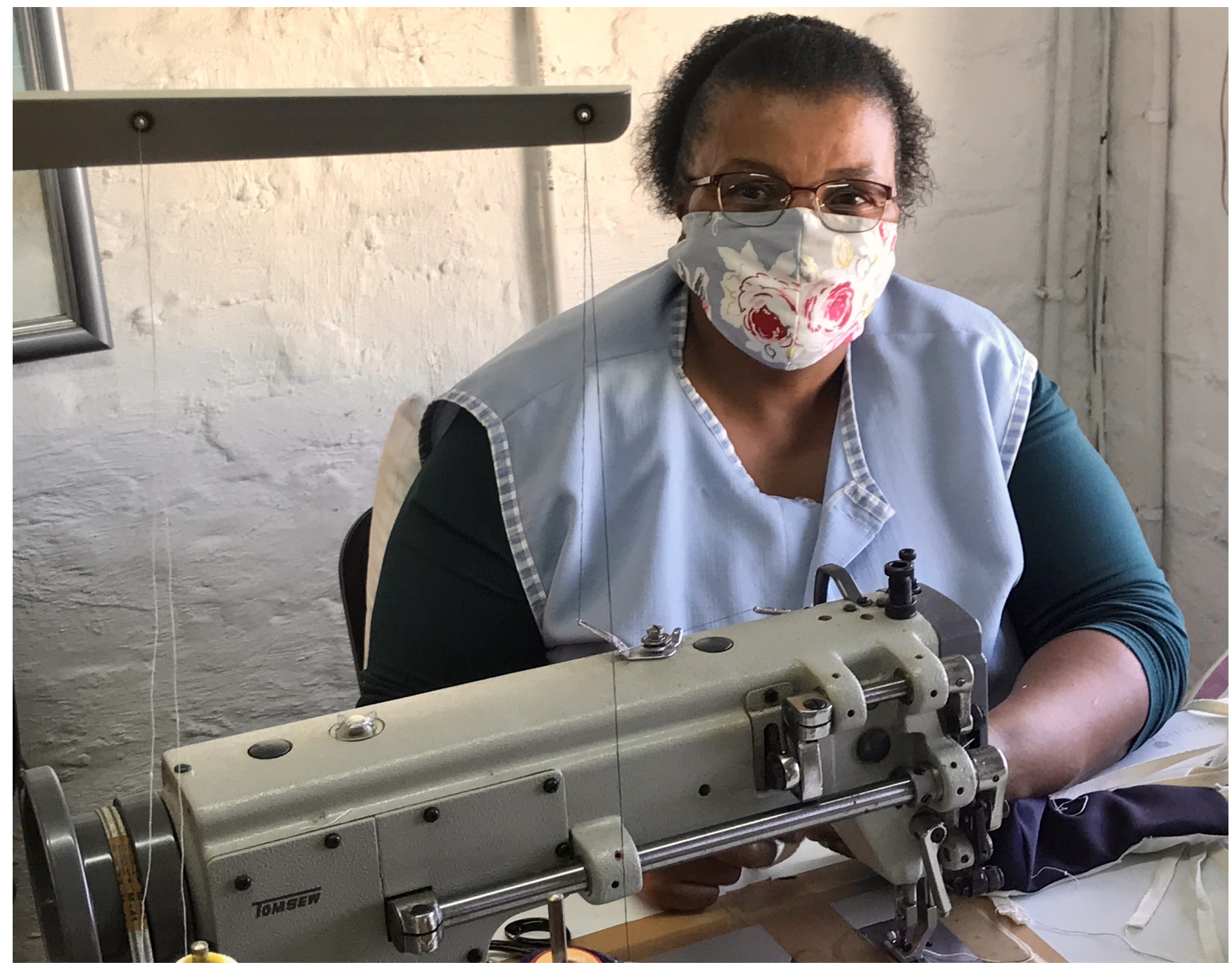

Fig 2 | A seamstress participating in a local \#Masks4All campaign in South Africa. Source: George Hospital Trust.

\section{Box 1: Examples of social practice approaches to promoting face coverings}

In the Czech Republic, a community led \#Masks4All advocacy campaign rapidly reshaped societal norms around the acceptability of wearing a face covering in public. "Mask trees" were used to distribute face coverings, and communities coordinated creating face coverings for each other. Social media were used to share messaging about making them at home, to show celebrity support for the campaign, to distribute songs to encourage their use, and to add humour through photos of public statues wearing face coverings. This created a movement, which prompted others to imitate this behaviour and follow the example. \#Masks4All slogans such as "keep your droplets to yourself" and "my mask protects you, your mask protects me" appealed to a shared set of social values. This sparked similar movements in other countries, including \#Masks4All campaigns in the US, South Africa, and Shelagh's Sewing Circle in the UK.

In South Africa it has been mandatory to wear a face covering when leaving your home since 1 May 2020. A key consideration has been managing access to face coverings, especially in rural areas with higher rates of poverty and unemployment. One of several locally focused, rural \#Masks4All campaigns in South Africa was led by George Hospital Trust in collaboration with non-profit organisation Azaria and members of the community who own sewing machines. Through this ongoing campaign they have fundraised, made, and distributed over 18000 face coverings to people who would otherwise have struggled to obtain them. This also creates job opportunities for women in need through the purchase of face coverings from Azaria and engages members of the public in making them as volunteers.

Embracing sociocultural narratives could enable the public to select a face covering that is meaningful to them and that they will be more likely to wear. Yet, a balance must be struck between encouraging customisation for comfort and acceptability and ensuring that the covering is sufficiently effective to block most viral transmission.

Cultural narratives are changing, though not universally. In some settings, a person who is not wearing a face covering is seen as a threat to the safety of others. ${ }^{15}$ This is generating new meanings of socially constructed deviance. ${ }^{18}$ As a community adopts face coverings, the first members wearing a face covering will be seen as deviant, but later those without coverings become deviants from the new norm. ${ }^{19}$ Two harm reduction researchers travelling from the UK to Thailand to attend a conference during the SARS outbreak described the persuasive influence of peer pressure in enhancing the use of face coverings as they transitioned between environments with contrasting norms around their use. ${ }^{19}$ Social norms around how deviance is tolerated are likely to vary between a society's 
tightness (for example, Singapore) and looseness (for example, Brazil) and can contribute to learning through the behaviour of others. ${ }^{13}$ Drawing on existing social and behavioural science research of previous respiratory epidemics and the experiences of countries where the use of face coverings have been widespread before this pandemic is key. ${ }^{20}$

\section{Conclusion}

Protracted debates about face coverings as a medical intervention have delayed implementation of a valuable preventive tool. Now that most countries have shifted to support face coverings to prevent transmission of covid-19, we must also shift the focus to implementation. Instead of continuing to debate technical specifications and efficacy, sociocultural framings should be explored to encourage their use. This can be done by emphasising underlying values such as solidarity and communal safety. Such measures are likely to enhance the uptake of face coverings and help curb the devasting impact of the pandemic.

Contributors and sources: HvdW is a medical doctor doing qualitative research about tuberculosis infection control measures. KK is a medical doctor and health systems researcher. ST-C is a health psychologist whose work focuses on infections and health related behaviours. NG is a social scientis whose work aims to advance epidemic relevant clinical and social research. TG is trained in global public health, health systems research, and social science; she has an academic interest in narrative review. She sits on the Scientific and Technical Advisory Committee of the World Health Organization Alliance for Health Policy and Systems Research. HvdW conceptualised the paper and wrote the first draft; she is the guarantor. Other authors provided additional ideas and contributed to a series of redrafts.

Patient involvement: This article was reviewed by Ingrid Schoeman, a member of TB Proof, who developed drug resistant tuberculosis and was asked to wear a mask during her treatment. She also used a mask to protect herself while she worked as dietitian in a public hospital. TB Proof is a tuberculosis advocacy organisation based in South Africa. It forms partnerships between patients with tuberculosis and researchers to improve TB prevention and care. Collaboration aims to combine stories and science and include public awareness campaigns, policy reviews, and training on TB infection control and advocacy.

Competing interests: We have read and understood BMJ policy on declaration of interests and have the following interests to declare: HvdW is chairperson of the board and does unpaid advocacy for the non-governmental organisation TB Proof, which includes work on tuberculosis stigma and infection control. STC and NG receive funding for research related to covid-19 from the European Commission H2020 (101003589) and the UK Research and Innovation Covid-19 Emergency Fund. They do not receive direct funds for work on this topic. NG is co-chair of the WHO Covid-19 Research Roadmap social science working group. The views expressed in this paper are those of the authors and do not necessarily reflect those of the working group. TG has written several articles promoting the wearing of face coverings by the lay public as source control in covid-19; she has received no direct funding for her work on this topic but is principal investigator on grants from National Institute for Health Research (BRC-1215-20008), UK Research and Innovation (Covid-19 Emergency Fund), and Wellcome Trust (WT104830MA)

Provenance and peer review: Not commissioned; externally peer reviewed.

We acknowledge the contributions of the WHO Covid-19 Research Roadmap social science working group who co-developed an earlier brief on considerations from the social sciences relevant to face coverings as source control. We thank George Hospital Trust and Azaria for sharing their approach to distributing face coverings in South Africa. We thank Ingrid Schoeman for her feedback on the article.

1 World Health Organization. Advice on the use of masks in the context of COVID-19: interim guidance-2. 2020. https://apps.who.int/iris/handle/10665/332293

2 Masks4All. What countries have mask laws? (2020). https://masks4all.co/what-countries-havemask-laws/.

3 Centers for Disease Control and Prevention. Recommendation regarding the use of cloth face coverings, especially in areas of significant community-based transmission. 2020. https://www.cdc.gov/coronavirus/2019-ncov/prevent-getting-sick/cloth-face-cover.html.

4 Cabinet Office United Kingdom. Guidance: Staying safe outside your home. Coronavirus (covid-19) guidance and support (2020). https://www.gov.uk/government/publications/staying-safe-outsideyour-home/staying-safe-outside-your-home.

$5 \quad$ World Health Organization. How to wear a non-medical face mask safely. 2020. https://www.who.int/images/default-source/health-topics/coronavirus/clothing-masks-infographic(web)-logo-who.png?sfvrsn=b15e3742_16.

6 Greenhalgh T. Face coverings for the public: laying straw men to rest. J Eval Clin Pract 2020;26:1070-7

7 World Health Organization. Advice on the use of masks in the context of COVID-19: interim guidance-1. 2020. https://apps.who.int/iris/handle/10665/331693
8 Rutter H, Wolpert M, Greenhalgh T. Managing uncertainty in the covid-19 era. BMJ Opinion2020 Jul 22. https://blogs.bmj.com/bmj/2020/07/22/managing-uncertainty-in-the-covid-19-era/

9 Shaw J, Shaw S, Wherton J, Hughes G, Greenhalgh T. Studying scale-up and spread as social practice: theoretical introduction and empirical case study. J Med Internet Res 2017;19: doi: 10.2196/jmir.7482 pmid: 28687532

10 Jindal SK, Aggarwal AN, Christopher DJ, Dhar R, Jindal A. Cloth face covers-a sustainable measure to mitigate COVID-19. Int J Tuberc Lung Dis 2020. https://www.theunion.org/news-centre/news/cloth-face-covers-a-sustainable-measure-to-mitigate-covid-19

11 Hansstein FV, Echegaray F. Exploring motivations behind pollution-mask use in a sample of young adults in urban China. Global Health 2018;14:122 doi: 10.1186/s12992-018-0441-y pmid: 30514342

12 Burgess A, Horii M. Risk, ritual and health responsibilisation: Japan's 'safety blanket' of surgical face mask-wearing. Sociol Health Illn 2012;34:1184-98. doi: 10.1111/j.1467-9566.2012.01466.x pmid: 22443378

13 Bavel JJV, Baicker K, Boggio PS, etal. Using social and behavioural science to support COVID-19 pandemic response. Nat Hum Behav 2020;4:460-71 doi: 10.1038/s41562-020-0884-z pmid: 32355299

14 Xio Z, Henley W, Boyle C, Gao Y, Dillon J. The face mask and the embodiment of stigma [Preprint]. PsyArXiv. 2020. https://psyarxiv.com/fp7z8/

15 MacFarquhar N. Who's enforcing mask rules? Often retail workers, and they're getting hurt. New York Times 2020. https://www.nytimes.com/2020/05/15/us/coronavirus-masks-violence.html?auth=login-email\&login=email.

16 Ball P. How mask-wearing became a new culture war. New Statesman 2020. https://www.newstatesman.com/politics/uk/2020/07/how-mask-wearing-became-new-culturewar.

17 Cheng KK, Lam TH, Leung CC. Wearing face masks in the community during the COVID-19 pandemic: altruism and solidarity. Lancet 2020; doi: 10.1016/S0140-6736(20)30918-1. pmid: 32305074

18 Brouillette JR, Turner RE. Creating the sociological imagination on the first day of class: the social construction of deviance. Teach Sociol 1992;20:276-9doi: 10.2307/1318968.

19 Syed Q, Sopwith W, Regan M, Bellis MA. Behind the mask. Journey through an epidemic: some observations of contrasting public health responses to SARS. J Epidemiol Community Health 2003;57:855-6. doi: 10.1136/jech.57.11.855 pmid: 14600109

20 The Royal Society and the British Academy. Face masks and coverings for the general public: Behavioural knowledge, effectiveness of cloth coverings and public messaging. 2020. https://royalsociety.org/-/media/policy/projects/set-c/set-c-facemasks.pdf?la=enGB\&hash=A22A87CB28F7D6AD9BD93BBCBFC2BB24

This article is made freely available for use in accordance with BMJ's website terms and conditions for the duration of the covid-19 pandemic or until otherwise determined by BMJ. You may use, download and print the article for any lawful, non-commercial purpose (including text and data mining) provided that all copyright notices and trade marks are retained. 